\title{
Congenital pulmonary arteriovenous malformation: A rare cause of cyanosis in childhood
}

\author{
H Mottaghi $^{1}$, M Kahrom ${ }^{2}$, M Hassan Nezafati ${ }^{2}$ and H Kahrom $^{2}$ \\ (Index words: pulmonary arteriovenous malformation, cyanosis, right to left shunting)
}

\section{Introduction}

Pulmonary arteriovenous malformations (PAVMs) are caused by abnormal communications between pulmonary arteries and pulmonary veins, which are most commonly congenital in nature. Although these lesions are uncommon, they are an important part of the differential diagnosis of common pulmonary problems such as hypoxaemia, pulmonary nodules and cyanosis.

PAVM is a rare disorder with an incidence of 2-3 per $1,000,000$ population [1]. It occurs twice as often in women as in men, but there is a male predominance in newborns. Around $10 \%$ cases of PAVM are identified in infancy or childhood, followed by a gradual increase in the incidence through the fifth and sixth decades. Approximately $70 \%$ of the cases of PAVM are associated with hereditary haemorrhagic telangiectasia (HHT). Conversely, about 15 to $35 \%$ of patients with HHT have PAVM. PAVMs may cause hypoxaemia and dyspnoea due to right to left shunting, but frequently remain undiagnosed. This intrapulmonary malformation is described in two patients who presented with severe cyanosis.

\section{Case reports}

\section{Patient 1}

A 6-month-old male infant was found to have a cardiac murmur and cyanosis of one day. He was born at term after a normal pregnancy and without prenatal complications. His family history was unremarkable and specifically negative for cardiopulmonary disorders. He had a dusky colour, but was relatively well and thriving. His mother related a history of orthodeoxia with worsening cyanosis when the infant was embraced, while the cyanosis improved when lying back. Cardiovascular examination showed bounding peripheral pulses in both upper and lower limbs, normal heart sounds and a continuous machinery murmur. The murmur was best heard at the left upper sternal border suggesting a patent ductus arteriosus (PDA). There was normal vesicular breathing. The examination of abdomen, central nervous system, skin and mucosa did not reveal any abnormality.

The arterial blood gas analysis (room air) showed a $\mathrm{pH}$ of $7.23, \mathrm{PCO}_{2}$ of $5 \mathrm{kPa}, \mathrm{HCO}_{3}$ of $17 \mathrm{mmol} / 1$, and $\mathrm{O}_{2}$ saturation of $61 \%$. Chest X-ray and ECG were normal. The haemoglobin was $11.8 \mathrm{~g} / \mathrm{dl}$ with normal methaemoglobin of $1.2 \%$.

Echocardiography confirmed the presence of a PDA, but it could not account for the cyanosis. Video assisted thoracoscopic surgery (VATS) for closure of PDA was done. As expected the PDA closure did not resolve the cyanosis and early clubbing. Therefore contrast echocardiographic study was performed. It suggested the presence of a PAVM with significant right to left shunt, as evidenced by rapid filling of the left atrium with dissolved bubbles. Cardiac catheterisation showed the pulmonary arteriovenous malformation in postero-basal segment of lower zone of the left lung (Figure1), with normal pulmonary artery pressure of $15 / 5 \mathrm{mmHg}$. Oxygen saturation of the aorta was $64 \%$, which made him a candidate for catheterbased intervention.

\footnotetext{
${ }^{1}$ Division of Cardiology, Department of Pediatrics, Imam Reza Hospital and ${ }^{2}$ Department of Cardiac Surgery, Imam Reza Hospital, Mashhad University of Medical Sciences, Mashhad, Iran.

Correspondence: MK, e-mail <kahrom@irimc.org>. Received 5 August and accepted 17 November 2009. Competing interests: none declared.
} 


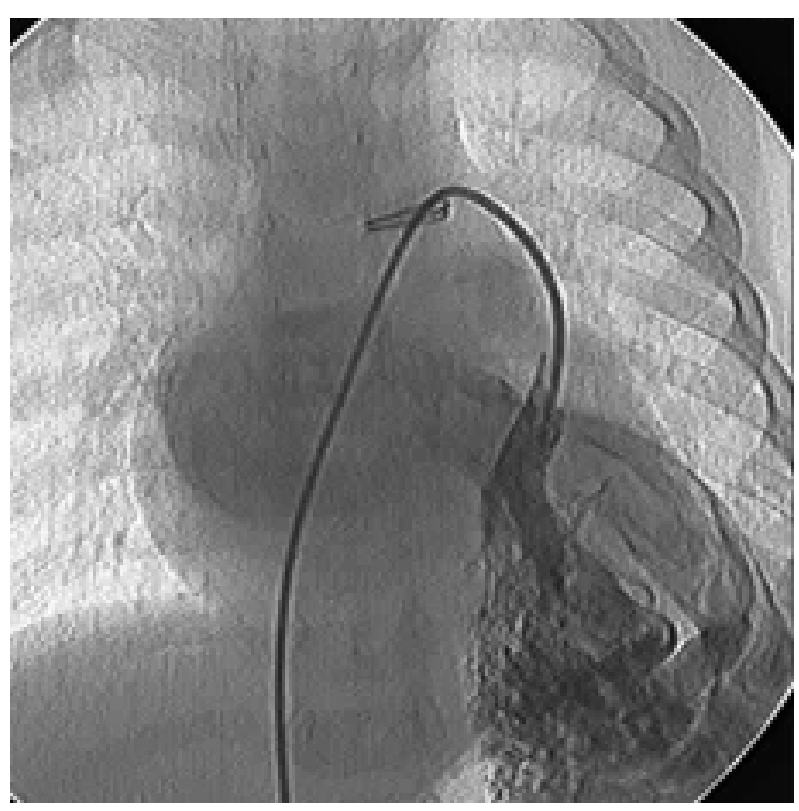

Figure 1. Selective angiography of the left lower lobe PAVM, showing a dilated feeding artery draining into a large vein, with rapid filling of the left atrium. Note the clips for PDA closure.

\section{Patient 2}

A 10-year-old girl was referred to the Department of Pediatric Cardiology with severe cyanosis. There was history of bluish discolouration of fingers and lips for past 5 years. There was no history of breathlessness.

On examination, patient was thin. The peripheral pulses and heart sounds were normal, with a normal blood pressure of $95 / 72$. There was central cyanosis and finger clubbing. There was no evidence of mucocutaneous telangiectasia. Examination of cardiopulmonary and nervous systems were normal. Haemoglobin was $16.8 \mathrm{~g} / \mathrm{dl}$ with normal methHb of $2 \%$. Chest X-ray and pulmonary function tests (PFTs) were reported to be normal by pulmonologists. Arterial blood gas analysis (room air) showed a $\mathrm{pH}$ of $7.20, \mathrm{PO}_{2}$ of $58.8 \%, \mathrm{PCO}_{2}$ of $40.3 \%$ and oxygen saturation of $88 \%$.

Contrast echocardiographic study did not show any significant anomaly. Cardiac catheterisation was performed and injection of contrast media into the main pulmonary artery showed immediate opacification of the left atrium and a small haziness in the left lung. Selective injection of contrast media to the left pulmonary artery demonstrated a PAVM in the superior lingula of the left lung (Figure 2). Thus she underwent transcatheter embolisation.

\section{Discussion}

Most PAVMs are congenital, frequently related to HHT, an autosomal dominant disorder. Abnormal communications between blood vessels of the lung may

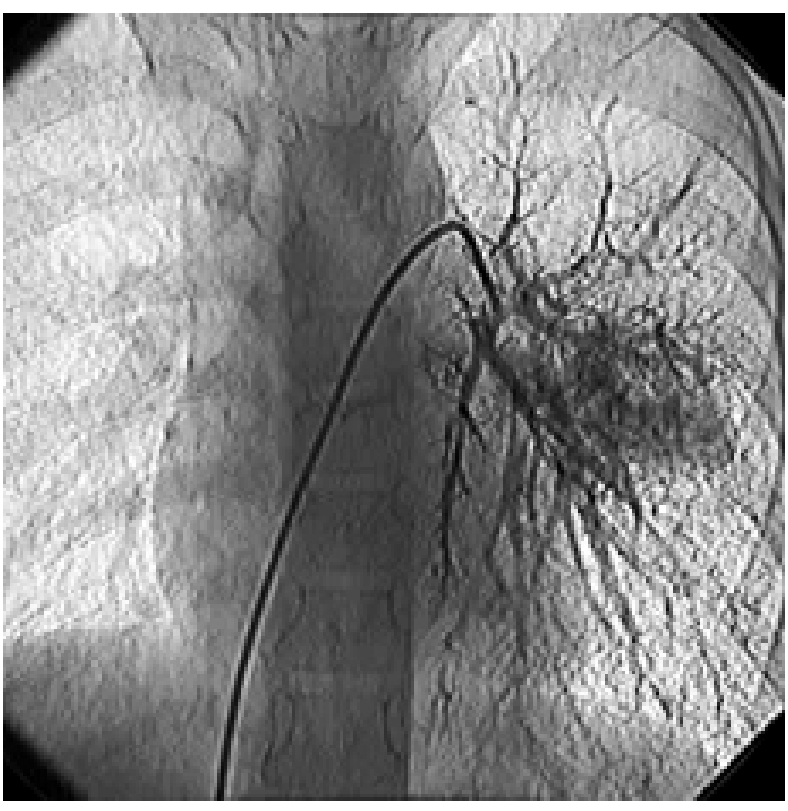

Figure 2. Anteroposterior projection of the left pulmonary artery injection, demonstrates simultaneous filling of the pulmonary artery, pulmonary capillary bed and pulmonary veins of the left lung. Note haziness of PAVM in superior lingula.

also be found in a variety of acquired conditions such as hepatic cirrhosis, schistosomiasis, mitral stenosis, trauma, actinomycosis, Fanconi's syndrome and metastatic thyroid carcinoma [2].

Fifty-three to seventy percent of PAVMs are found in lower lobes, $75 \%$ of patients have unilateral disease, $36 \%$ have multiple lesions, and half of those with multiple lesions have bilateral disease. PAVMs are supplied by pulmonary arteries in about $95 \%$ of cases, and by systemic arteries less frequently.

Symptoms in early life may vary from asymptomatic to severe cyanosis, congestive heart failure and even fulminant respiratory failure. Symptoms related to PAVM often develop between the 4th and 6th decades. Progression of PAVMs is often noted during pregnancy [3]. A progressive increase in cyanosis is often noted because of the opening of new or enlargement of the existing fistula, and development of polycythemia. Haemoptysis and haemothorax may occur, especially in patients with HHT and in pregnancy. Neurologic sequelae may occur in up to $33 \%$ of patients with HHT [4].

Chest X-ray may show one or more rounded multilobular opacities when the fistulae are large. Cardiomegaly may be present rarely, when the fistulae are very large and cause a hyperdynamic state. However, the chest film is not a very sensitive diagnostic modality. Pulse oxymetry is usually abnormal, with various degrees of desaturation but it may not detect small fistulae. The most sensitive non-invasive screening test for PAVMs, either in the context of complex congenital heart disease or in 
patients with HHT, is contrast echocardiography [5]. Radionuclide testing using $\mathrm{Tc}^{99 \mathrm{~m}}$ labeled albumin microspheres is also a useful test, which can provide a quantitative measurement of the right to left shunt by measuring the fraction of the injected dose of microspheres reaching the kidneys [6]. Chest computed tomography may demonstrate PAVMs accurately. Recently, contrast enhanced magnetic resonance angiography was compared to helical CT. It was found to be sensitive (75\%) and specific (100\%). Despite advances in the techniques mentioned, contrast pulmonary angiography remains the gold standard in diagnosis of PAVM, and is usually necessary before resectional or obliterative therapy. Three forms of management are available for the various types of PAVMs: (1) transcatheter embolization therapy (using coils, detachable balloons, and various devices designed for occlusion of atrial septal defects) (2) surgical approach, (lobectomy, segmentectomy, fistulectomy, redirection of hepatic venous flow to the pulmonary circulation, and heart or heart/lung transplantation) and (3) medical therapy in a few cases.

The diagnosis of PAVM should be considered in infants with severe cyanosis without structural cardiac lesions or pulmonary hypertension, after excluding other causes of cyanosis, such as parenchymal lung disease and the rare methaemoglobinaemia. A high index of suspicion is required for a successful echocardiographic diagnosis of PAVM in a cyanotic infant with the use of contrast echocardiography. Pulmonary angiography is mandatory whenever a diagnosis of PAVM is suspected in order to confirm the diagnosis and a precise identification of the number and location of all lesions before embolization or surgical intervention is undertaken.

\section{References}

1. Gossage JR, Kanj G. Pulmonary arteriovenous malformation: a state of art review. American Journal of Respiratory Critical Care Medicine 1998; 158: 643-61.

2. Lange PA and Stoller JK. The hepatopulmonary syndrome. Annals of International Medicine 1995; 122: 521-9.

3. Gershon AS, Faughan ME, Chon KS, et al. Transcatheter embolotherapy of maternal pulmonary arteriovenous malformations during pregnancy. Chest 2001; 119: 470-7.

4. Moussouttas M, Fayad P, Rosenblatt M, et al. Pulmonary arteriovenous malformations: cerebral ischemia and neurologic manifestations. Neurology 2000; 55: 959-64.

5. Nanthakumar K, Graham AT, Robinson TI, et al. Contrast echocardiography for detection of hereditary hemorrhagic telangiectasia. American Heart Journal 2001; 141: 243-6.

6. Chilvers ER, Peters AM, George P. Quantification of rightto-left shunt through pulmonary arteriovenous malformations using Tc albumin microspheres. Clinical Radiology 1988; 39: 611-4. 